\title{
Bispectral index value correlates with Glasgow Coma Scale in traumatic brain injury patients
}

\author{
This article was published in the following Dove Press journal: \\ Open Access Emergency Medicine \\ 10 April 2017 \\ Number of times this article has been viewed
}

\author{
Tjokorda Gde Agung \\ Senapathi \\ Made Wiryana \\ I Gusti Ngurah Mahaalit \\ Aribawa \\ Christopher Ryalino \\ Department of Anesthesiology and \\ Intensive Care, Udayana University, \\ Sanglah General Hospital, Denpasar, \\ Bali, Indonesia
}

Correspondence: Christopher Ryalino Department of Anesthesiology and Intensive Care, Udayana University, Sanglah General Hospital, Jalan Diponegoro, Denpasar 801 14, Bali, Indonesia

Email ryalino@gmail.com
Background: Accuracy of consciousness level assessment is very important. It may determine and influence further clinical decisions, thus influences patients' outcomes. The widest method in determining the level of awareness is the Glasgow Coma Scale (GCS). Despite its common use, GCS scores obtained by one clinician may differ from others depending on their interpretations and past experience. One of the tools used to assess the level of consciousness objectively is bispectral index (BIS). The aim of this study was to identify the correlation between BIS and GCS score in patients with traumatic brain injury.

Patients and Methods: A total of 78 patients who were admitted to emergency room for traumatic brain injury were included in this study. One observer evaluated the GCS of all patients to minimize subjectivity. Another investigator then obtained the BIS values for each patient. Spearman's rank correlation coefficient was used to determine whether GCS correlated with BIS value. Results: In 78 patients, the BIS was found to be significantly correlated with GCS ( $r=0.744$, $p<0.01)$. The BIS values increased with an increasing GCS. Mean BIS values of mild, moderate, and severe head injury were $88.1 \pm 5.6,72.1 \pm 11.1$, and $60.4 \pm 11.7$, respectively.

Conclusion: In this study, a significant correlation existed between GCS and BIS. This finding suggests that BIS may be used for assessing GCS in patients with traumatic brain injury. However, the scatters of BIS values for any GCS level may limit the BIS in predicting GCS accurately.

Keywords: decreased consciousness, head injury, BIS monitor, consciousness level, anesthesia depth, prediction, association

\section{Introduction}

Traumatic brain injury (TBI) is one common case found in emergency department. It is the leading cause of death in productive age. Its rate is sharply increasing in recent years along with the increased use of motor vehicles, especially in low- to middleincome countries. TBI is defined as an alteration in brain function, or other evidence of brain pathology, caused by an external force. ${ }^{1}$

Assessing the consciousness level is a very important step in managing patients with TBI. An accurate assessment leads to proper decision for intervention, which leads to better outcomes. One method used for assessing the level of consciousness is the Glasgow Coma Scale (GCS), first defined by Sir Graham Tisdale and Bryan Jennet in $1974 .^{2}$

Even after $>40$ years, GCS is still the most common method used by clinicians all over the world today in assessing consciousness level. Its main features are that 
it is simple, easy to perform, and not requiring any special diagnostic tools. Despite its wide use, some limitations have been reported.

One of the most mentioned limitations is the high interobserver variability. ${ }^{3-7}$ When 116 patients were examined by 2 emergency physicians, only $55 \%-74 \%$ of paired measurements were identical and $6 \%-17 \%$ of them were 2 or more points apart. ${ }^{4}$ In 73 level I trauma centers surveyed about what point they assigned in intubated patients, $26 \%$ gave 1 point for verbal component, $23 \%$ gave 3 points for total GCS of intubated patients, and $16 \%$ assigned a " $\mathrm{T}$ " for verbal component. ${ }^{4}$

The bispectral index (BIS) is a processed electroencephalogram (EEG) parameter with extensive validation and demonstrated clinical utility. It is derived by using a composite of measures from EEG signal processing techniques including bispectral analysis, power spectral analysis, and time domain analysis. These measures were combined through an algorithm to optimize the correlation between the EEG and the clinical effects of anesthesia. ${ }^{8}$

The aims of this study were to determine whether BIS score correlates with GCS score and to determine the mean of BIS values in each severity class of head-injured patients.

\section{Patients and methods}

This study was conducted from September to October 2016 at the emergency department of Sanglah Public General Hospital in Bali Island, Indonesia. This study was approved by the Research Ethics Committee of Sanglah General Hospital and Udayana University. All the patients or their guardians have provided written informed consent to be included in this study.

A total of 78 patients with decreased consciousness due to head injury were included. Patients with mental disturbance, previous history of impaired hearing or speech, alcoholic state, medically sedated, hypoglycemia (blood sugar level $<70$ $\mathrm{g} / \mathrm{dL}$ ), severe hyponatremia (serum sodium $<118 \mathrm{mmol} / \mathrm{L}$ ), hypoxia $\left(\mathrm{SaO}_{2}<90 \%\right)$, current or previous state of shock, and those whose GCS score was 3 with no brainstem activities were excluded.

Data were obtained upon emergency room admission, after emergency procedures were conducted. Both GCS and BIS values for the purpose of this study were obtained once, with the BIS measured no longer than 5 minutes after the GCS was evaluated. To reduce variability between interpreters, one observer evaluated the consciousness level of all patients. Another observer, with no information about the GCS level, obtained the BIS value with BIS monitor Model A-3000 Vista with Sensor BIS Quatro (Aspect Medical Sys- tem, Norwood, MA, USA). The BIS score was included if the Signal Quality Index was $>75 \%$ and the electromyography score was $<50 \%$.

Kolmogorov-Smirnov test was used to evaluate data normality. Correlation between BIS and GCS scores was evaluated by using Spearman's correlation test. A $p$-value $\leq 0.05$ was considered statistically significant.

\section{Results}

A total of 78 patients were enrolled in this study. The characteristics of the eligible subjects are presented in Table 1. The average age of the patients was 24 years, ranged from 16 to 65 years. Of the 78 patients, $64(82.1 \%)$ were male, and the remaining $(17.9 \%)$ were female.

Road accident $(80.8 \%)$ was the most common cause of head injury, followed by falls $(7.7 \%)$ and occupational accidents $(5.1 \%)$. Twenty-one $(26.9 \%)$ patients were admitted because of mild head injury, whereas 30 (38.5\%) and 27 (34.6\%) patients were admitted for moderate and severe head injury, respectively.

A strong positive correlation was found between BIS and GCS by using Spearman's correlation test $(r=0.744, p<0.01)$ as shown in Table 2. Scatter plot between BIS values and GCS

Table I Characteristics of the subjects

\begin{tabular}{ll}
\hline Characteristics & Value \\
\hline Age (years), median (IQR) & $24(22)$ \\
Sex & \\
$\quad$ Male, n (\%) & $64(82.1 \%)$ \\
Female, n (\%) & $14(17.9 \%)$ \\
Education & \\
Elementary school or lower, n (\%) & $2(2.6 \%)$ \\
Middle high school, n (\%) & $10(12.8 \%)$ \\
High school, n (\%) & $62(79.5 \%)$ \\
Graduate or post-graduate, n (\%) & $4(5.1 \%)$ \\
Mechanism of head injury & \\
Road accident, n (\%) & $62(80.8 \%)$ \\
Occupational accident not related to traffic, n (\%) & $4(5.1 \%)$ \\
Falls, n (\%) & $6(7.7 \%)$ \\
Unknown, n (\%) & $4(5.1 \%)$ \\
Others, n (\%) & $2(1.3 \%)$ \\
Severity & \\
Mild head injury, n (\%) & $21(26.9 \%)$ \\
Moderate head injury, n (\%) & $30(38.5 \%)$ \\
Severe head injury, n (\%) & $27(34.6 \%)$ \\
\hline Abbrevtion: &
\end{tabular}

Abbreviation: IQR, interquartile range.

Table 2 Spearman's correlation analysis between BIS value and GCS

\begin{tabular}{llll}
\hline Variables & Median (IQR) & $\boldsymbol{R}$ & p-value \\
\hline BIS value & $72.5(22)$ & 0.744 & $<0.01$ \\
GCS score & $10.0(7)$ & & \\
\hline
\end{tabular}

Abbreviations: BIS, bispectral index; GCS, Glasgow Coma Scale; IQR, interquartile range. 


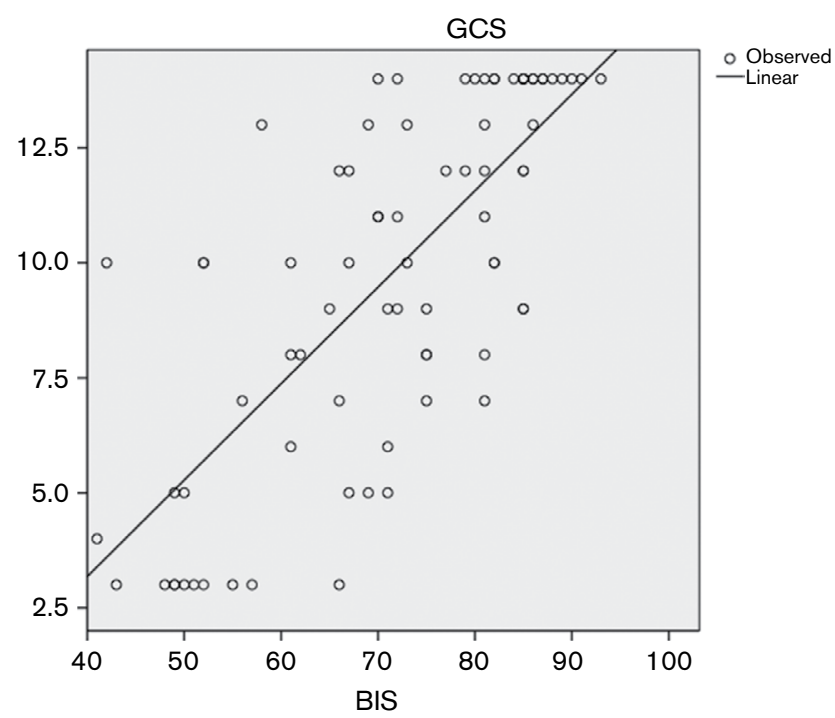

Figure I Scatter plot display for correlation between GCS and BIS values. Abbreviations: BIS, bispectral index; GCS, Glasgow Coma Scale.

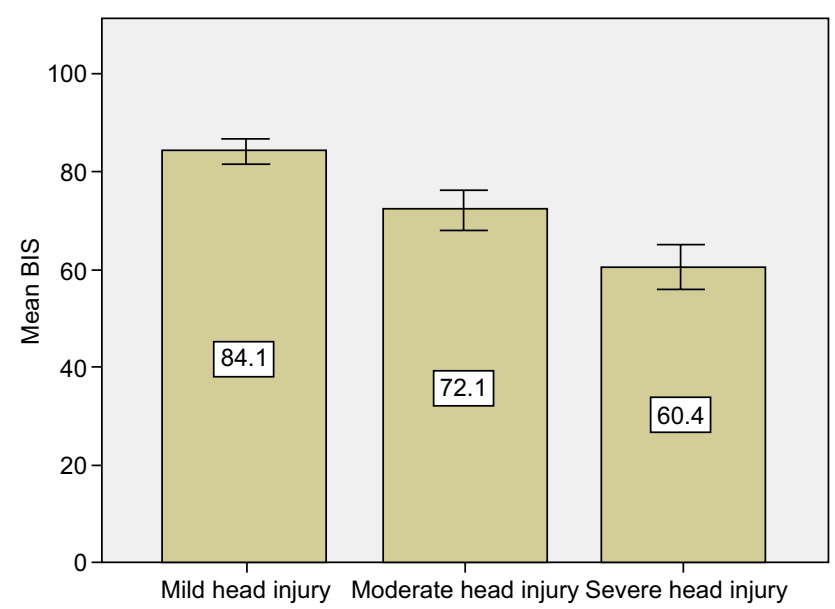

Figure 2 Mean BIS values for mild, moderate, and severe head injury (mean \pm SD). Abbreviations: BIS, bispectral index; SD, standard deviation.

scores is shown in Figure 1. The mean BIS values for mild, moderate, and severe head injury were $84.1 \pm 5.6,72.1 \pm 11.1$, and $60.4 \pm 11.7$, respectively. Mean BIS values at different head injury severity levels are shown in Figure 2.

A linear regression correlation was analyzed between BIS and GCS as shown in Table 3. Table 4 showed mean BIS value for each severity level of brain injury. Then an equation was derived to see whether the GCS score can be predicted by knowing the BIS value. This study formulated an equation: $\mathrm{GCS}=0.21(\mathrm{BIS})-5.208$. It was found that mean BIS values in mild, moderate, and severe head injury were $84.1 \pm 5.6$, $72.1 \pm 11.1$, and $60.4 \pm 11.7$, respectively.

\section{Discussion}

The BIS has been widely used in operating theaters to measure the hypnotic effects of anesthesia drugs. ${ }^{3,8}$ The
Table 3 Linear regression correlation between BIS and GCS

\begin{tabular}{lllll}
\hline Variables & $\boldsymbol{\beta}$ & $\mathbf{9 5 \%} \mathbf{C l}$ & $\boldsymbol{p}$-value & $\boldsymbol{R}^{\mathbf{2}}$ \\
\hline BIS & 0.21 & $0.166-0.253$ & $<0.01$ & $55 \%$ \\
Constant & -5.208 & &
\end{tabular}

Abbreviations: $\mathrm{BIS}$, bispectral index; $\mathrm{Cl}$, confidence interval.

Table 4 Mean BIS value for each severity level of brain injury $($ mean \pm SD)

\begin{tabular}{lll}
\hline Head injury & Mean \pm SD & $\mathbf{9 5 \%} \mathbf{C l}$ \\
\hline Mild & $84.1 \pm 5.6$ & $81.58-86.7 \mathrm{I}$ \\
Moderate & $72.1 \pm \mathrm{II} . \mathrm{I}$ & $67.99-76.28$ \\
Severe & $60.4 \pm \mathrm{II} .7$ & $55.78-65.03$ \\
\hline
\end{tabular}

Abbreviations: BIS, bispectral index; $\mathrm{Cl}$, confidence interval; SD, standard deviation.

BIS monitor is first introduced by Aspect Medical System (USA) in 1994 as a way to measure consciousness level in anesthetized patients. Prospective clinical trials have demonstrated that maintaining BIS values in the range between 40 and 60 ensures adequate hypnotic effect during general anesthesia. ${ }^{9}$ BIS is internally recalculated in every 0.5 second, by using an interval of 2 seconds with $75 \%$ overlap. The value showed on screen is updated every second. BIS used an internal window of change, which causes delay in displaying the information, with a duration of 15 seconds. ${ }^{10}$

Lately, its use is expanding in ICU for assessing consciousness level in sedated patients and also to predict the neurological outcome in brain-injured patients, along with auditory evoked potentials, EEG, and somatosensory evoked potentials (SSEPs). ${ }^{3,11}$

This study limits the time interval between GCS evaluation and BIS recording to no more than 5 minutes. ${ }^{12}$ Excessive skeletal muscle movement has been known to create inconsistency in BIS reading. Although a shorter interval may ensure that the correlation is more representative, the BIS readings may be influenced by the movement from the motoric evaluation of GCS.

This study was designed to determine the correlation between GCS level and BIS scores. It was found that BIS scores showed strong significant correlation with GCS level. Interestingly, although BIS scores were highly correlated with GCS, the BIS scores for each GCS level were widely scattered.

Results of this study correspond well with those of earlier studies, which reported that a significant correlation exists between GCS and BIS. Jung et $\mathrm{al}^{3}$ showed good correlation between BIS and GCS $(r=0.726, p<0.01)$, they also showed 
that mean BIS value increased with increasing level of consciousness.

Paul and Umamaheswara published similar results, where they found GCS and BIS were significantly correlated $(r=0.67, p<0.01) .{ }^{13}$ They discovered that mean BIS value arises accordingly to the increase of GCS score. They also reported that the mean BIS values for mild and moderate head injury were $65.7 \pm 16.1$ and $85.7 \pm 6.1$, respectively, which also correspond well to the results of the present study.

Gill et $\mathrm{al}^{14}$ reported that BIS value was weakly correlated with GCS $(r=0.387)$. They identified the problem with this weak correlation was the wide variability of BIS values corresponding to GCS. The wide BIS value variability finding was also consistent with the results of the present study as shown in Figure 1.

This study produced an equation that may be used to predict one's GCS score from a certain BIS level: GCS = 0.21 (BIS) - 5.208. In conditions where GCS is not possible to assess, this formula may be helpful in determining one's consciousness level. However, the widely scattered BIS value for each GCS score may suggest that further studies with large number of subjects are required in order to validate this formula. Certain doubts may arise because BIS algorithm was calibrated from anesthetized patients rather than brain trauma patients.

\section{Conclusion}

BIS value is highly correlated with GCS score in TBI patients. An equation to predict GCS from a BIS value derived from the linear regression analysis: GCS $=0.21$ (BIS) -5.208 . Further studies with larger number of subjects are required in order to extend and deepen the understanding about the correlation between BIS and GCS, as to investigate whether a certain BIS value may exactly predict GCS score independently.

\section{Disclosure}

The authors report no conflicts of interest in this work.

\section{References}

1. Menon DK, Schwab K, Wright DW, Maas AI. Position statement: definition of traumatic brain injury. Arch Phys Med Rehabil. 2010;91: 1637-1640.

2. Teasdale G, Allan D, Brenan P, McElhinney E, Mackinnon L. Forty years on: updating the Glasgow Coma Scale. Nurs Times. 2014;110(42):12-16

3. Jung JY, Cho CB, Min BM. Bispectral index monitoring correlates with the level ofconsciousness in brain injured patients. Korean JAnesthesiol. 2013;64(3):246-250.

4. Matis G, Birbilis T. The Glasgow Coma Scale - a brief review. Past, present, future. Acta Neurol Belg. 2008;108:75-89.

5. Buechler CM, Blostein PA, Koestner A, Hurt K, Schaars M, McKernan J. Variation among trauma centers' calculation of Glasgow Coma Scale score: results of a national survey. J Trauma. 1998;45:429-432.

6. Meredith W, Rutledge R, Fakhry SM, Emery S, Kromhout-Schiro S. The conundrum of the Glasgow Coma Scale in intubated patients: a linear regression prediction of the Glasgow verbal score from the Glasgow eye and motor scores. J Trauma. 1998;44:839-844.

7. Rutledge R, Lentz CW, Fakhry S, Hunt J. Appropriate use of the Glasgow Coma Scale in intubated patients: a linear regression prediction of the Glasgow verbal score from the Glasgow eye and motor scores. JTrauma. 1996;41:514-522.

8. Dou L, Gao H, Lu L, Chang W. Bispectral index in predicting the prognosis of patients with coma in intensive care unit. World J Emerg Med. 2014;5(1):53-56.

9. Fabregas N, Gambus PL, Valero R, et al. Can bispectral index monitoring predict recovery of consciousness in patients with severe brain injury? Anesthesiology. 2004;101:43-51.

10. Nunes RR, Chaves IM, de Alencar JC, Franco SB, de Oliveira YG, de Menezes DG. Bispectral index and other processed parameters of electroencephalogram: an update. Rev Bras Anestesiol. 2012;62(1):105-117.

11. Wang XF, Zhang LS, Wu DW. Prediction of neurological outcome using bispectral index in patients with severe acute brain injury. Turk J Med Sci. 2013;43:718-725.

12. Nasraway SA, Wu EC, Kelleher RM, Yasuda CM, Donnelly AM. How reliable is the bispectral index in critically ill patients? A prospective, comparative, single-blinded observer study. Crit Care Med. 2002;30(7):1483-1487.

13. Paul DB, Umamaheswara Rao GS. Correlation of bispectral index with Glasgow Coma score in mild and moderate head injuries. J Clin Monit Comput. 2006;20:399-404.

14. Gill M, Green SM, Krauss B. Can the bispectral index monitor quantify altered level of consciousness in emergency department patients? Acad Emerg Med. 2003;10:175-179.
Open Access Emergency Medicine

\section{Publish your work in this journal}

The Open Access Emergency Medicine is an international, peerreviewed, open access journal publishing original research, reports, editorials, reviews and commentaries on all aspects of emergency medicine. The manuscript management system is completely online and includes a very quick and fair peer-review system, which is all

\section{Dovepress}

easy to use. Visit http://www.dovepress.com/testimonials.php to read real quotes from published authors. 